\title{
Biology Teaching Self-Efficacy Beliefs of the Teacher Candidates
}

\author{
Cem GERÇEK*, Miraç YILMAZ ${ }^{* *}$ \\ Pinar KÖSEOĞLU ${ }^{* * *}$, Haluk SORAN ${ }^{* * * *}$
}

\begin{abstract}
The main aim of this study is to determine the level of biology teaching self-efficacy beliefs of the teacher candidates. "The Scale of Self-Efficacy in Science Teaching" which was developed by Enochs and Riggs in 1990 and adapted to the Turkey's conditions by B1kmaz in 2002 was used.

Working group consists of 159 teacher candidates from the Division of Biology Education in Hacettepe University Faculty of Education in 2003-2004 academic year. The analysis of the data was conducted with t, ANOVA and overage. In the study, the self-efficacy belief of biology teacher candidates was determined to be high $(X=3.75)$. There was a huge difference in the level of belief selfefficacy of teacher candidates between different classes and by reason of job choose.
\end{abstract} candidate.

Key Words: Self-efficacy, biology teacher, and biology teacher

\footnotetext{
*Arş. Gör. Dr. Hacettepe University, cgercek@ hacettepe.edu.tr

** Yrd. Doç. Dr. Hacettepe University, mirac@ hacettepe.edu.tr

*** Öğr. Gör. Dr. Hacettepe University, pakbulut@ hacettepe.edu.tr

***** Prof. Dr. Hacettepe University, soran@ hacettepe.edu.tr
} 


\section{SUMMARY}

Behavior, main concern of pedagogues, is also a main concern of many other studies. Self-efficacy that explains how an individual perceives himself/herself is also thought to have an effect on the understanding of behavior. It is a common point of view that the teachers trained institutions where the teachers are educated should be willing, self-sacrificing and capable of handling problems on their owns. It is important that the belief in self-efficacy of teacher candidates, which affects motivation and performance, be determined and improved.

The main target of this study is to determine the level of biology teaching self-efficacy of the students in Hacettepe University Faculty of Education Division of Biology Education, and examine them for various changeable.

\section{Method}

\section{The Model of the Research}

The research has a descriptive form to determine the self-efficacy of the students in the HU Faculty of Education, Biology Education.

\section{Scale and Sampling}

The scale of the research is composed of 240 students who study in the HU Faculty of Education, Biology Education in the academic year of 20032004 and the sampling is composed of 159 students that could be reached out of the scale.

\section{Data Collecting Tool}

"Self-efficacy scale in Science Teaching" which was designed by Enochs and Riggs (1990) was used in order to measure class teacher candidates' self-efficacy belief in science teaching and adapted for Turkish standards in 2002 by B1kmaz after the "science" statement was changed to "biology". The credibility coefficient of the adapted scale is 8.5.

\section{Operation}

The data-collecting tool was applied to the students of Hacettepe University, Department of Biology Education during the lesson periods by three investigators. After the students were informed of the practice, the data-collecting tool was used. The practices took place in 20-30 minute periods with the accession of 159 biology education students. 
The data have been analyzed with SPSS 10.0 program. Arithmetical mean and standard deviations have been calculated for the variables. In order to find out if there is any difference between variables, the " $\mathrm{t}$ " test in the .05 meaning level and one-sided variance analysis have been applied. The differences between classes have been determined through LSD test.

\section{Findings}

The self-efficacy point average of the male and female teacher candidates studying at the Hacettepe University, Division of Biology Education is 3,75 and standart deviation is detected to be .35 . the highest point to be received is detected to be 5 .

When self efficiency beliefs of biology teacher candidates in biology teaching are examined in line with gender, age, academic achievement, high school from which teacher candidates graduate, location where the high school is situated and monthly salaries of the families; no considerable difference has been observed.

\section{Discussion}

Results of the research show that self-efficacy beliefs of H.U. biology teacher candidates in biology teaching are high. Given that self-efficacy belief may affect teacher behaviors such as efforts, feed-back and teaching in order to meet the requirements of the field (Gibson and Dembo, 1984; Enochs and Riggs, 1990), it could be proposed that the essence, content and quality of the biology teaching provided by teacher candidates will be greater on the condition that biology teaching self-efficacy belief is high.

When self efficiency beliefs of biology teacher candidates in biology teaching are examined in line with gender, age, academic achievement, high school from which teacher candidates graduate, location where the high school is situated and monthly salaries of the families; no considerable difference has been observed. self-efficacy beliefs in biology teaching don't constitute any difference in accordance with the high school type from which teacher candidates graduate. This is striking especially for teachers' high schools.

Biology teaching self-efficacy beliefs of the students who graduate from teachers' high school aren't higher than the other high schools. This finding indicates that preparatory programs, which these students attend, don't make any difference in terms of biology teaching self-efficacy belief. Akkoyunlu and Orhan (2003), through their research in which they examine computer self-efficacy belief, propose that grads from computer department of vocational high schools have higher computer-use self-efficacy belief than 
other high school grads because they are equipped with a better and more comprehensive computer education.

It is strange that there is no clear-cut difference between self-efficacy beliefs of biology teacher candidates in biology teaching in accordance with academic achievement. Yavuzer and Koç (2002) state that self-efficacy beliefs of teacher candidates increase on the condition that their academic achievements are high. According to self-efficacy theory of Bandura (1977), one of the basic sources on which self-efficacy belief depends is performance achievement. Through this research, academic achievements of biology teacher candidates don't affect biology teaching self-efficacy beliefs. This finding shows that H.U. biology teacher candidates don't consider evaluations, which reveal academic achievements, as performance achievements.

It has been observed that there is a clear difference between selfefficacy beliefs of teacher candidates in biology teaching according to classes. Classes affect self-efficacy belief of biology teaching while there is no considerable effect of age. This finding shows that experience gained during the school are important in terms of biology teaching self-efficacy. Indeed, this situation is of great importance because biology education programs have important effects on self-efficacy beliefs of teacher candidates. Ashton (1984) states that education programs should serve different purposes other than content of the lesson or methodology for prospective teachers.

In terms of biology teaching self-efficacy belief, teacher candidates who prefer this profession because $\mathrm{s} / \mathrm{he}$ wants to be a teacher are more advantageous. Given the benefits of selfefficacy belief, it is stressed that this preference should be taken into account while selecting people who want to become teacher. This finding indicates that self-efficacy beliefs of students who are interested in this profession are high. Preference of this profession because students want to be teacher has an important effect on biology teaching selfefficacy belief. This situation shows that there is a direct relation between reason for preference and self-efficacy. This finding indicates that there could be a relation between selfefficacy and behaviors. 


\title{
Biyoloji Eğitimi Öğretmen Adaylarının Öğretiminde Öz-Yeterlik İnançları
}

\author{
Cem GERÇEK*, Miraç YILMAZ ${ }^{* *}$ \\ Pinar KÖSEOĞLU ${ }^{* * *}$, Haluk SORAN ${ }^{* * * *}$
}

\begin{abstract}
ÖZ: $\mathrm{Bu}$ çalışmanın amacı, öğretmen adaylarının biyoloji öğretimi öz-yeterlik inancı düzeylerini belirlemek ve çeşitli değişkenler açısından incelemektir.

Betimsel yapıda olan araştırmada Enochs ve Riggs (1990) tarafından geliştirilen ve Bıkmaz tarafından 2002 yılında Türkiye koşullarına uyarlanan "Fen Öğretiminde Öz-yeterlik İnancı Ölçeği" kullanılmıştır. Çalışma grubunu 2003-2004 öğretim yılında Hacettepe Üniversitesi Eğitim Fakültesi, Biyoloji Eğitimi Ana Bilimdalı'nda okuyan 159 öğretmen adayı oluşturmaktadır. Verilerin analizi ortalama, ANOVA ve t testi ile gerçekleştirilmiştir.
\end{abstract}

Araștırmada, öğretmen adaylarının biyoloji öğretiminde özyeterlik inançlarının yüksek $(X=3.75)$ düzeyde olduğu belirlenmiştir. Sınıflara ve meslek tercih nedenine göre biyoloji ögretmen adaylarının öz-yeterlik inancı puanları arasında .05 düzeyinde anlamlı bir fark bulunmuştur. Öğretmen adaylarının cinsiyet, yaş, mezun olunan lise türü, yerleşim birimi, aylık gelir ve başarı öz-yeterlik inançları arasında anlamlı bir farklılık bulunamamıştır.

Anahtar Kelimeler: Öz-yeterlik, biyoloji öğretimi, biyoloji öğretmen adayı

\footnotetext{
*Arş. Gör. Dr. Hacettepe Üniversitesi, cgercek@ hacettepe.edu.tr

** Yrd. Doç. Dr. Hacettepe Üniversitesi, mirac@ hacettepe.edu.tr

*** Öğr. Gör. Dr. Hacettepe Üniversitesi, pakbulut@ hacettepe.edu.tr

***** Prof. Dr. Hacettepe Üniversitesi, soran@ hacettepe.edu.tr
} 


\section{GİRIŞ}

Kişinin kendini algılamasını açıklayan kavramlardan biri olan özyeterlik, bu yapıyı ilk kez tanımlamış olan Bandura'ya (1994) göre, "bireyin belli bir performansı göstermek için gerekli etkinliği organize edip, başarılı olarak yapma kapasitesine duyduğu inanç" olarak ifade edilmektedir. Davranışlar; insanlar belli bir davranışın istendik sonuçlar vermesini beklediğinde (sonuç beklentisi) ve davranışı yapma yeteneklerine inandıklarında (öz-yeterlik inançları) gerçekleşir. Araştırmalar, öz-yeterliğin kişisel hedefler, tepkiler ve analitik stratejileri kullanma performansını artırdığı ve bireyin motivasyonunu etkilediğini göstermektedir. Öz-yeterlik, bireyin faaliyetleri seçmesinde ve zor durumlarda ne kadar süre çaba göstereceğinde önemli oranda etkilidir. Öz-yeterlik inancı yüksek olan kişilerin engellerle karşılaştıklarında daha hızlı toparlanabildikleri ve hedeflerine bağlılıklarını sürdürdükleri belirtilmektedir (Bandura, 1977; Bandura, 1994; Schmitz\&Schwarzer, 2000; Scholz at al., 2002).

Çağdaş eğitim ilkeleri doğrultusunda görev yapan bir öğretmenin, Oğuzkan'a (1984) göre, artık sadece ders anlatan, sınav yapan ve not veren biri olamayacağı vurgulanmaktadır (Baksan, 2001). Öğretmen inançlarının incelenmesinin, öğretmen davranışını daha eksiksiz anlamada hayati önem taşıdığ1 bildirilmiştir (Riggs\&Enochs, 1990). Öğretmen öz-yeterlik beklentisi, öğretmenlerin öğretme işlevini başarılı bir şekilde yerine getirebilmek için gerekli davranışları gösterecekleri konusundaki inanışları olarak tanımlanmaktadır (Atıcı, 2000). Öz-yeterlik konusunda, davranışların oluşumunda etkili olan iki boyuttan ilki olan öz-yeterlik inançları, öğretmenlerin olumlu değişimler yaratma yeteneklerine ilişkin değerlendirmelerini; sonuç beklentisi ise öğretmenin çevreyi ne ölçüde kontrol edebileceğine inandığını yansıtır. Etkili öğretim yoluyla öğrenmenin etkilenebileceğine inanan ve ayrıca öğretme yeteneklerine güvenen öğretmenlerin daha uzun süre sebat edeceği ve farklı dönütler vereceği belirtilmektedir (Gibson\&Dembo, 1984). Schmitz (2000), öz-yeterli öğretmenlerin mesleklerine daha çok yönelen ve memnuniyeti yüksek öğretmenler olduklarını söylemektedir.

Bazı araştırmalarda, öğretmenlerin değişik öğrenci gruplarında kendilerini daha etkili bulduğu ve öz-yeterliğin derse göre değiştiği bildirilmektedir (Riggs\&Enochs, 1990). Biyoloji öğretimine yönelik özyeterlik, öğretmenlerin biyoloji öğretimini etkili ve verimli bir şekilde yapabileceklerine ve öğrencinin başarısını artırabileceklerine yönelik kendi yetenekleri hakkındaki yargı ve inançları olarak tanımlanabilir. Savran ve Çakıroğlu (2001) çalışmalarında, ODTÜ Biyoloji öğretmen adaylarının özyeterlik inançlarının yüksek olduğunu tespit etmişlerdir. Biyoloji öğretmen 
adaylarının öğrencilerin başarılarının etkili öğretme yöntemleriyle artırılabileceğine olan inançlar (sonuç beklentisi) ve kendilerinin etkili bir öğretme için gerekli davranışları gösterecekleri konusundaki sahip oldukları inançlar (öz-yeterlik inançları), öğretimde ortaya koyacakları çaba açısından oldukça önemlidir (Bandura, 1977; Savran ve Çakıroğlu, 2001). Böylelikle öğretmen adaylarının gelecekte mesleklerinde gösterecekleri performans ve çabaları ile ilgili bir tahmin yapılabileceği gibi; eğitim programlarının öğretmenlerin bu yönden gelişimine dair düzenlemeleri de içerecek şekilde yeniden gözden geçirilmesi de sağlanabilir. Bu çalışma, Biyoloji Eğitimi Ana Bilimdalı'nda okuyan öğretmen adaylarının biyoloji öğretimindeki özyeterliklerini belirlemeyi ve çeşitli değişkenler açısından incelemeyi amaçlamaktadır.

Araştırmanın problem cümlesi; H.Ü. Eğitim Fakültesi Biyoloji Eğitimi ABD öğretmen adaylarının biyoloji öğretimi öz-yeterlik inançları nasıldır? Araştırmanın alt problemleri ise; H.Ü. Eğitim Fakültesi Biyoloji Eğitimi ABD öğretmen adaylarının biyoloji öğretimi öz-yeterlikleri; a) cinsiyetlerine, b) yaşlarına, c) sınıflarına, d) mezun oldukları lisenin türüne, e) mezun oldukları lisenin bulunduğu yerleşim birimine, f) ailelerinin gelirlerine, g) öğretmenlik mesleğini tercih nedenlerine ve h) akademik başarılarına göre farklılık göstermekte midir?

\section{YÖNTEM}

\subsection{Araştırmanın Modeli}

Araştırma, öğretmen adaylarının biyoloji öğretiminde öz-yeterlik inançlarını belirlemeye yönelik betimsel bir yapıdadır.

\section{2. Çalışma Grubu}

Araştırmanın çalışma grubunu 2003-2004 eğitim-öğretim yılında H.Ü. Eğitim Fakültesi Biyoloji Eğitimi ABD'nda öğrenim gören 240 öğretmen adayından ulaşılabilen 159 öğretmen adayı oluşturmaktadır.

\subsection{Veri Toplama Aracı}

Araştırmada, Enochs ve Riggs (1990) tarafından sınıf öğretmeni adaylarının fen öğretiminde öz-yeterlik inancını ölçmek için geliştirilen ve Bıkmaz tarafından 2002 yılında Türkiye koşullarına uyarlanan, "Fen Öğretiminde Öz-yeterlik Ölçeği” "fen" ifadesi "biyoloji” ile değiştirilerek kullanılmıştır.

Ölçeğin Türkçe'ye adaptasyonunda 10 alan uzmanından görüş alınmıştır. Daha sonra ölçeğin önce orjinali daha sonrada çevirisi 24 öğretmen adayına uygulanmış Türkçe ve orijinal ölçekteki madde 
eşdeğerlilik katsayıları .68 olarak bulunmuştur. Maddeler eşdeğer kabul edilerek Türkçe ölçek 279 kişiden oluşan başka bir gruba uygulanarak iki ölçeğin eşdeğer olarak kabul edilebileceği görüşüne varılmıştır.

Ölçek iki boyutta toplam 21 maddeden oluşmaktadır. Ölçeğin yapı geçerliliği için temel bileşenler analizi kullanılarak, faktör analizi yapılmıştır. Daha sonra varimax dik döndürme tekniği kullanılmıştır. Uyarlanan ölçeğin bütünü için güvenirlik katsayısı .85 'tir.

Ölçeğin uygulanması 2003-2004 öğretim döneminde Biyoloji Eğitimi ABD’ndaki tüm sınıflardan tabakalı örnekleme yöntemiyle seçilen 159 öğretmen adayında gerçekleştirilmiştir.

\subsection{Verilerin Analizi}

Veriler SPSS 10.0 programından yararlanılarak analiz edilmiştir. Değişkenler için aritmetik ortalama ve standart sapmalar bulunmuştur. Değişkenler arasında fark olup olmadığı .05 anlamlık düzeyinde verilerin standart normal dağıldığı ve kişi sayısı yeterli olduğundan dolayı parametrik testlerden iki değişken için bağımsız " $\mathrm{t}$ " testi ve daha çok değişken için ANOVA kullanılarak belirlenmiştir.

\section{BULGULAR}

\section{1. Öğretmen Adaylarının Öz-yeterlikleri}

Araştırmaya katılan 159 öğretmen adayının öz-yeterlik puanlarının aritmetik ortalaması ve standart sapması Tablo 1'de verilmiştir. Öz-yeterlik ortalaması 3.75 olarak bulunmuş olup, ölçekten alınabilecek en yüksek puan 5 'tir. Öz-yeterlik puanlarının standart sapması ise .35 olarak hesaplanmıştır.

Tablo1. Öğretmen adaylarının öz-yeterliklerine ilişkin sonuçlar

\begin{tabular}{cll}
\hline $\mathbf{N}$ & $\overline{\mathbf{X}}$ & $\mathbf{S}$ \\
\hline 159 & 3.75 & .35 \\
\hline
\end{tabular}

\subsection{Cinsiyete Göre Öz-Yeterlik}

Tablo 2'de kız ve erkek öğretmen adaylarının öz-yeterlik puanlarına ilişkin aritmetik ortalamaları, standart sapmaları ve " $t$ " değeri ve önemlilik düzeyi verilmişsir. Cinsiyetin etkisi .05 düzeyinde istatistiksel olarak anlamlı değildir $[\mathrm{t}(1,1.08)=0.28, \mathrm{p}<.05]$. 
Biyoloji Ĕ̌itimi Öğretmen Adaylarının Biyoloji Öğretiminde ...

Tablo 2. Öğretmen adaylarının cinsiyete göre öz-yeterlik t testi sonuçları

\begin{tabular}{cccccc}
\hline Cinsiyet & $\mathbf{N}$ & $\overline{\mathrm{X}}$ & $\mathbf{S}$ & $\mathbf{t}$ & $\mathbf{p}$ \\
\hline Kadın & 126 & 3.77 & .36 & \multirow{2}{*}{1.08} & .28 \\
Erkek & 33 & 3.70 & .31 & \\
\hline
\end{tabular}

$$
\mathrm{p}<.05
$$

\subsection{Yaşa Göre Öz-Yeterlik}

Tablo 3 ve 4'de öğretmen adaylarının yaşlarına göre öz-yeterlik puanları arasında farklılığa ilişkin aritmetik ortalama, standart sapma ve varyans analizi sonuçları verilmiştir. Yaşın etkisi .05 düzeyinde istatistiksel olarak anlamlı değildir $[\mathrm{F}(1,1.1)=0.36, \mathrm{p}<05]$.

Tablo 3. Yaşa göre öz-yeterliğe ilişkin aritmetik ortalama ve standart sapmalar

\begin{tabular}{lccc}
\hline Yaş & $\mathbf{N}$ & $\overline{\mathbf{X}}$ & $\mathbf{S}$ \\
\hline 20 ve altı & 59 & 3.70 & .40 \\
21-22 & 49 & 3.78 & .32 \\
23 ve üzeri & 51 & 3.79 & .31 \\
Toplam & 159 & 3.75 & .35 \\
\hline
\end{tabular}

Tablo 4. Yaşa göre öz-yeterliğe ilişkin varyans analizi sonuçları

\begin{tabular}{llllll}
\hline VK & KT & Sd & KO & F & p \\
\hline Gruplar aras1 & .27 & 2 & .14 & & \\
Gruplar içi & 19.06 & 156 & .12 & 1.102 & .36 \\
Toplam & 19.33 & 158 & - & & \\
\hline
\end{tabular}

$\mathrm{p}<.05$

\subsection{Sinıfa Göre Öz-Yeterlik}

Sınıflara göre öz-yeterlik puanları arasında farklılığa ilişkin aritmetik ortalama, standart sapma ve varyans analizi sonuçları Tablo 5 ve 6'da verilmiştir. Tablo 6'da görüldüğü gibi, farklı sınıfların etkisi .05 düzeyinde istatistiksel olarak anlamlıdır $[\mathrm{F}(1,2.4)=0.03, \mathrm{p}<05]$. Hangi sınıf düzeyleri arasında fark olduğunu bulmak için yapılan LSD testi sonuçlarına göre 3. sınıf biyoloji öğretimi öz-yeterlik ortalaması ( $X=3.90)$, hazırlık sınıfı, 1. sınıf ve 4. sınıf biyoloji öğretimi öz-yeterlik ortalamalarından (sırasıyla $\mathrm{X}=3.64 ; \quad \mathrm{X}=3.68 ; \quad \mathrm{X}=3.70$ ) yüksektir. 5. sınıf biyoloji öğretimi öz-yeterlik ortalaması $(X=3.87)$, hazırlık sınıfı ve 1. sınıf biyoloji öğretimi öz-yeterlik ortalamalarından (sirasıyla $\mathrm{X}=3.64 ; \mathrm{X}=3.68$ ) yüksektir. 
Tablo 5. Sınıfa göre öz-yeterliğe ilişkin ortalama ve ve standart sapmalar

\begin{tabular}{cccc}
\hline Sinıf & $\mathbf{N}$ & $\overline{\mathbf{X}}$ & $\mathbf{S}$ \\
\hline Hazırlık & 24 & 3.64 & .53 \\
1. Sinıf & 32 & 3.68 & .33 \\
2. Sinıf & 19 & 3.81 & .26 \\
3. Sinıf & 23 & 3.90 & .27 \\
4. Sinıf & 37 & 3.70 & .27 \\
5. Sinıf & 24 & 3.87 & .34 \\
Toplam & 159 & 3.75 & .35 \\
\hline
\end{tabular}

Tablo 6. Sınıfa göre öz-yeterliğe ilişkin varyans analizi sonuçları

\begin{tabular}{cccccc}
\hline VK & KT & Sd & KO & F & p \\
\hline Gruplar arasi & 1.43 & 5 & .29 & & \\
Gruplar içi & 17.90 & 153 & .12 & 2.45 & .03 \\
Toplam & 19.32 & 158 & - & & \\
\hline
\end{tabular}

$\mathrm{p}<.05$

\subsection{Mezun Olunan Lise Türüne Göre Öz-Yeterlik}

Mezun olunan lise türüne göre öz-yeterlik puanları arasında farklılığa ilişkin aritmetik ortalama, standart sapma ve varyans analizi sonuçları Tablo 7 ve 8 'de verilmiştir. Mezun olunan lise türünün etkisi .05 düzeyinde istatistiksel olarak anlamlı değildir $[\mathrm{F}(1,0.8)=0.44, \mathrm{p}<05]$.

Tablo 7. Mezun olunan lise türüne göre öz-yeterliğe ilişkin aritmetik ortalama ve standart sapmalar

\begin{tabular}{lccc}
\hline \multicolumn{1}{c}{ Lise türü } & N & $\bar{X}$ & S \\
\hline Genel Lise & 105 & 3.76 & .30 \\
Öğretmen Lisesi & 15 & 3.83 & .40 \\
Anadolu ve Fen Lisesi & 39 & 3.70 & .44 \\
Toplam & 159 & 3.75 & .35 \\
\hline
\end{tabular}

Tablo 8. Mezun olunan lise türüne göre öz-yeterliğe ilişkin varyans analizi sonuçları

\begin{tabular}{cccccc}
\hline VK & KT & Sd & KO & F & p \\
\hline Gruplar arasi & .2 & 2 & .10 & & \\
Gruplar içi & 19.1 & 156 & .12 & .82 & .44 \\
Toplam & 19.3 & 158 & - & & \\
\hline
\end{tabular}

$\mathrm{p}<.05$ 


\subsection{Mezun Olunan Lisenin Bulunduğu Yerleşim Birimine Göre Öz- Yeterlik}

Mezun olunan lisenin bulunduğu yerleşim birimine göre öz-yeterlik puanları arasında farklılığa ilişkin aritmetik ortalama, standart sapma ve varyans analizi sonuçları Tablo 9 ve 10'da verilmiştir. Mezun olunan lisenin bulunduğu yerleşim biriminin etkisi .05 düzeyinde istatistiksel olarak anlamlı değildir $[\mathrm{F}(1,0.56)=0.46, \mathrm{p}<05]$.

Tablo 9. Mezun olunan lisenin bulunduğu yerleşim birimine göre öz-yeterliğe ilişkin aritmetik ortalama ve standart sapmalar

\begin{tabular}{cccc}
\hline Yerleşim Birimi & $\mathbf{N}$ & $\overline{\mathbf{X}}$ & $\mathbf{S}$ \\
\hline İl & 108 & 3.77 & .35 \\
İlçe & 51 & 3.72 & .44 \\
Toplam & 159 & 3.75 & .35 \\
\hline
\end{tabular}

Tablo 10. Mezun olunan lisenin bulunduğu yerleşim birimine göre öz-yeterliğe ilişkin varyans analizi sonuçları

\begin{tabular}{cccccc}
\hline VK & KT & Sd & KO & F & p \\
\hline Gruplar arası & .0685 & 1 & .06846 & & \\
Gruplar içi & 19.26 & 157 & .123 & .56 & .46 \\
Toplam & 19.33 & 158 & - & & \\
\hline
\end{tabular}

$\mathrm{p}<.05$

\subsection{Ailelerin Aylık Gelirlerine Göre Öz-Yeterlik}

Ailelerin aylık gelirlerine göre öz-yeterlik puanları arasında farklılığa ilişkin aritmetik ortalama, standart sapma ve varyans analizi sonuçları Tablo 11 ve 12 'de verilmiştir. Ailelerin aylık gelirlerinin etkisi .05 düzeyinde istatistiksel olarak anlamlı değildir $[\mathrm{F}(1,0.73)=0.53, \mathrm{p}<05]$.

Tablo11. Aylık gelire göre öz-yeterliğe ilişkin aritmetik ortalama ve standart sapmalar

\begin{tabular}{lccc}
\hline \multicolumn{1}{c}{ Aylık gelir (YTL) } & $\mathbf{N}$ & $\overline{\mathrm{X}}$ & $\mathbf{S}$ \\
\hline 499 ve altı & 22 & 3.76 & .27 \\
$500-999$ & 87 & 3.75 & .31 \\
$1.000-1.499$. & 34 & 3.81 & .35 \\
1.500. ve üzeri & 16 & 3.65 & .57 \\
Toplam & 159 & 3.75 & .35 \\
\hline
\end{tabular}


Tablo 12. Aylık gelire göre öz-yeterliğe ilişkin varyans analizi sonuçları

\begin{tabular}{cccccc}
\hline VK & KT & Sd & KO & F & p \\
\hline Gruplar arası & .27 & 3 & .0901 & & \\
Gruplar içi & 19.055 & 155 & .123 & .73 & .53 \\
Toplam & 19.325 & 158 & - & & \\
\hline
\end{tabular}

$\mathrm{p}<.05$

\section{8. Öğretmenlik Mesleğini Tercih Nedenlerine Göre Öz-Yeterlik}

Öğretmen adaylarının öğretmenlik mesleğini tercih nedenlerine göre özyeterlik puanları arasında farklılığa ilişkin aritmetik ortalama, standart sapma ve varyans analizi sonuçları Tablo 13 ve 14'de verilmiştir. Tablo 14'de öğretmen adaylarının öğretmenlik mesleğini tercih nedenlerinin .05 düzeyinde istatistiksel olarak anlamlı olduğu görülmektedir $[\mathrm{F}(1,8.3)=$ $0.00, \mathrm{p}<05]$. Hangi tercih düzeyler arasında fark olduğunu bulmak için yapılan LSD testi sonuçlarına göre tercih nedeni öğretmen olmak istediğim için cümlesi ile ailem istediği için cümlesi arasındaki fark anlamlıdır. Tercih nedeni "öğretmen olmak istediğim için" olan öğretmen adaylarının biyoloji öğretimi öz-yeterliği puan ortalaması $(\bar{X}=3.87)$ yüksek iken, tercih nedeni "ailem istediği için" olan, tercih nedeni "iş bulunabildiği için" olan, tercih nedeni "açıkta kalmamak için" olan öğretmen adaylarının biyoloji öğretimi öz-yeterlik puan ortalaması (sirasıly $\bar{X}=3.48 ; \bar{X}=3.58 ; \bar{X}=3.67$ ) düşüktür. Tercih nedeni "öğretmen olmak istediğim için" olan öğretmen adaylarının biyoloji öğretimi öz-yeterlik puan ortalaması diğer tercih nedenlerinden daha yüksektir.

Tablo 13. Mesleği tercih nedenine göre öz-yeterliğe ilişkin aritmetik ortalama ve standart sapmalar

\begin{tabular}{lccc}
\hline \multicolumn{1}{c}{ Tercih nedeni } & $\boldsymbol{N}$ & $\overline{\mathrm{X}}$ & $\mathbf{S}$ \\
\hline Öğretmen olmak istediği için & 80 & 3.87 & .35 \\
Aile istediği için & 6 & 3.48 & .27 \\
İş bulunabildiği için & 26 & 3.58 & .28 \\
Açıkta kalmamak için & 46 & 3.67 & .33 \\
Toplam & 158 & 3.75 & .35 \\
\hline
\end{tabular}


Tablo 14. Mesleği tercih nedenine göre öz-yeterliğe ilişkin varyans analizi sonuçları

\begin{tabular}{cccccc}
\hline VK & KT & Sd & KO & F & p \\
\hline Gruplar arası & 2.6 & 3 & .893 & & \\
Gruplar içi & 16.5 & 154 & .108 & 8.3 & .00 \\
Toplam & 19.2 & 157 & - & & \\
\hline
\end{tabular}
$\mathrm{p}<.05$

\subsection{Akademik Başarıya Göre Öz-Yeterlik}

Akademik başarıya göre öz-yeterlik puanları arasında farklılığa ilişkin aritmetik ortalama, standart sapma ve varyans analizi sonuçları Tablo 15 ve 16 'da verilmiştir. Akademik başarının etkisi .05 düzeyinde istatistiksel olarak anlamlı değildir $[\mathrm{F}(1,2.1)=0.09, \mathrm{p}<05]$.

Tablo 15. Akademik başarıya göre öz-yeterliğe ilişkin aritmetik ortalama ve standart sapmalar

\begin{tabular}{cccc}
\hline Akademik Başart & $\mathbf{N}$ & $\overline{\mathrm{X}}$ & $\mathbf{S}$ \\
\hline $0.00-0.99$ & 3 & 3.81 & .38 \\
$1.00-1.99$ & 25 & 3.66 & .33 \\
$2.00-2.99$ & 89 & 3.78 & .29 \\
$3.00-4.00$ & 18 & 3.89 & .32 \\
Toplam & 135 & 3.77 & .31 \\
\hline
\end{tabular}

Tablo 16. Akademik başarıya göre öz-yeterliğe ilişkin varyans analizi sonuçları

\begin{tabular}{cccccc}
\hline VK & KT & Sd & KO & F & p \\
\hline Gruplar aras1 & .59 & 3 & .19 & & \\
Gruplar içi & 11.96 & 131 & .091 & 2.1 & .093 \\
Toplam & 12.56 & 134 & - & & \\
\hline
\end{tabular}

$\mathrm{p}<.05$

\section{TARTIŞMA VE ÖNERILER}

Araştırma sonuçları, incelenen biyoloji öğretmen adaylarının biyoloji öğretimindeki öz-yeterlik inançlarının yüksek olduğunu göstermektedir. Özyeterlik inancının çaba, dönüt verme ve alana özgü öğretim verebilme gibi öğretmen davranışlarını etkileyebileceği (Gibson\&Dembo, 1984; Enochs\&Riggs,1990) düşünülürse, biyoloji öğretimi öz-yeterliği inancının yüksek olmasının öğretmen adaylarının verecekleri biyoloji öğretiminin niteliğini artıracağı söylenebilir.

Biyoloji öğretmen adaylarının biyoloji öğretimindeki öz-yeterlik inançları cinsiyete, yaşa, akademik başarılarına, mezun olunan lise türüne, 
mezun olunan lisenin bulunduğu yerleşim birimine ve ailelerin aylık gelirlerine göre incelendiğinde anlamlı bir farklılık bulunamamıştır.

Biyoloji öğretimindeki öz-yeterlik inançlarının mezun olunan lise türüne göre fark göstermemesi, özellikle öğretmen liseleri açısından dikkat çekicidir. Öğretmen lisesi mezunu öğrencilerin biyoloji öğretimi öz-yeterlik inançlarının diğer liselere oranla yüksek çıkmaması, bu öğrencilerin lise eğitimleri boyunca aldıkları mesleğe hazırlayıcı programların biyoloji öğretimi öz-yeterliği inancı açısından fark yaratacak düzeyde olmadığını göstermektedir.

Biyoloji öğretmen adaylarının biyoloji öğretimindeki öz-yeterlik inançlarında akademik başarılarına göre anlamlı bir farklılık bulunmaması dikkat çekicidir. Yavuzer ve Koç (2002) çalışmalarında öğretmen adaylarının akademik başarıları yükseldikçe öz-yeterlik inançlarının arttığını bildirmişlerdir. Bandura'nın (1977) öz-yeterlik kuramına göre öz-yeterlik inancının dayandığı başlıca kaynaklardan biri performans başarılarıdır. Araştırmada biyoloji öğretmen adaylarının akademik başarılarının biyoloji öğretimi öz-yeterlik inançlarında fark yaratmaması, akademik başarıyı ortaya koyan değerlendirmelerin biyoloji öğretmen adayları tarafından performans başarısı olarak algılanmadığını düşündürmektedir.

Öğretmen adaylarının biyoloji öğretimindeki öz-yeterlik inançlarında sınıflara göre anlamlı bir farklılık tespit edilmiştir. Biyoloji öğretimi özyeterlik inancının yaşa göre farklılık göstermeyip sınıfa göre farklılık göstermesi, her sınıfta kazanılan deneyimin biyoloji öğretimi öz-yeterliği açısından önemli olduğunu göstermektedir. Aslında bu durum biyoloji eğitim programlarının da öğretmen adaylarının öz-yeterlik inançlarında fark yaratma açısından önemini ortaya koymaktadır. Ashton (1984) eğitim programlarının geleceğin öğretmenlerine dersin içeriği ve öğretim yönteminden fazlasını sunması gerektiğini söylemektedir.

Biyoloji öğretimi öz-yeterlik inancında, öğretmenlik mesleğini "öğretmen olmak istediği için” tercih eden öğretmen adayları lehine farklılık olması, öz-yeterlik inancının olumlu etkileri düşünüldüğünde, bu tercih nedeninin öğretmen olacak kişilerin seçiminde dikkate alınması gerekliliğini bir kez daha vurgulamaktadır. Bu durum, öğretmenlik mesleğine ilgi duyan ve olumlu tutum içinde olan öğretmen adaylarının öz-yeterlik inançlarının da yüksek olacağını göstermektedir. Öğretmen olmak istediği için öğretmenliği tercih etmenin, biyoloji öğretimi öz-yeterlik inancında fark yaratması tercih nedeni ile öz-yeterlik arasında önemli bir ilişki olduğunun göstergesidir. Bu ise, öz-yeterlik ile derse karşı tutumları arasında bir bağıntının olabileceğini düşündürmektedir. 
Bu bulgular ışığında, öğretmen adaylarının biyoloji öğretimi öz-yeterlik inançlarını daha iyi bir düzeye getirebilmek için aşağıdaki konular önerilebilir:

- Biyoloji öğretimi öz-yeterlik inançlarının sınıfa göre farklılık göstermesi, okulda kazanılan deneyimin ve biyoloji eğitim programlarının önemini ortaya koyduğundan, üniversitelerdeki eğitim programları belli dönemlerde biyoloji öğretimi öz-yeterlik inancı açısından değerlendirilebilir.

- Biyoloji öğretimi öz-yeterlik inancında, öğretmenlik mesleğini "öğretmen olmak istediği için” tercih eden öğretmen adayları lehine farklılık olduğundan, daha sonraki araştırmalarda biyoloji öğretimi bakımından derse yönelik tutumun öz-yeterlik inancı üzerindeki etkisi ve aralarındaki ilişki ayrıntılı bir şekilde araştırılabilir. 


\section{KAYNAKLAR}

Ashton, P. (1984). Teacher efficacy: A motivational paradigm for effective teacher education. Journal of Teacher Education, 35, 28-32.

Atıcı, M. (2000). İlkokul Öğretmenlerinin Sınıf Yönetiminde Yetkinlik Beklentisi Rolünün İngiltere ve Türkiye' de seçilen Bir Araştırma Grubu Üzerinde İncelenmesi. YOK-Online, [Online]: www.yok.gov.tr/egfak/meral.htm, adresinden 4 Mayıs 2003 tarihinde indirilmiştir.

Bandura, A. (1977). Self-Efficacy: Toward A Unifying Theory Of Behavioral Change. Psychogical Review, 84 (2), 191-215.

Bandura, A. (1994). Self-efficacy, In V.S. Ramachaudran(Ed.), Encyclopedia of Human Behavior (pp. 71-81), Newyork: Academic Press.

Baskan, G.A. (2001). Öğretmenlik Meslĕgi Ve Öğretmen Yetiştirmede Yeniden Yapılanma. Ankara: Denge Mat L.Ş.

Bıkmaz, F. H. (2002). Fen Öğretiminde Öz-yeterlik İnancı Ölçeği. Eğitim Bilimleri ve Uygulama, 1 (2), 197-210

Enochs L. G., and Riggs, I. M. (1990). Further Development of an Elementary Science Teaching Efficacy Belief Instrument: A Preservice Elementary Scale. School Science and Mathematics, 90 (8), 694-706.

Gibson, S., Dembo, M.H. (1984). Teacher Efficacy: A Construct validation. Journal of Educational Psychology, 76, 569-582.

Riggs, I. M., and Enochs L. G. (1990). Toward The Development of an Elementary Teacher's Science Teaching Efficacy Belief Instrument. Science Education, 74 (69), 625-637.

Savran, A., Çakıroğlu, J. (2001). Preservice Biology Teachers' Perceived Efficacy Beliefs In Teaching Biology. Hacettepe Üniversitesi Eğitim Fakültesi Dergisi, 21, 105-112.

Schmitz, G.S. (2000). "Zur Sturuktur und Dynamik der Selbstwirksamkeitserwartung von Lehrern. Ein protektiver Faktor gegen Belastung und Burnout?" Diggitale Dissertation. FU Berlin. [Online] retrieved on 12-March-2001, at URL: http://darwin.inf.fuberlin.de/2000/29/ 
Schmitz, G.S. und Schwarzer, R. (2000). Selbstwirksamkeitserwartung von Lehrern: Längsschnitt-befunde mit einem neuen Instrument. Zeitschrift für Pädagogische Psychologie, 14 (1),12-25.

Scholz, U., Dona, B.G., Sud, A., Schwarzer, R. (2002), Is General SelfEfficacy a Universal Construct?, European Journal of Psychological Assesment, 18(3), 242-251.

Yavuzer, Y., Koç, M. (2002). Eğitim Fakültesi Öğrencilerinin Öğretmen Yetkinlikleri Üzerinde Bir Değerlendirme. Niğde Üniversitesi Eğitim Fakültesi Dergisi, 1 (1), 35-43. 